\title{
Long-term Strategies for Diabetes Prevention: Evaluation of the Group Lifestyle Balance Post-Core Sessions Focusing on Carbohydrate and Hunger Management
}

\author{
Kramer M Kaye ${ }^{1 *}$, Venditti Elizabeth $\mathbf{M}^{2}$, Semler Linda $\mathbf{N}^{3}$, Kriska Andrea $\mathbf{M}^{1}$, Miller Rachel $\mathbf{G}^{1}$ and Orchard Trevor $\mathbf{J}^{1}$
}

${ }^{1}$ University of Pittsburgh, Graduate School of Public Health, Department of Epidemiology, USA

2 University of Pittsburgh, Department of Psychiatry, USA

${ }^{3}$ University of Pittsburgh, School of Education, USA

\begin{abstract}
The Group Lifestyle Balance (GLB) program, adapted from the Diabetes Prevention Program lifestyle intervention, has demonstrated effectiveness in reducing risk factors for diabetes and cardiovascular disease. Although overall carbohydrate quality was addressed in the GLB program, carbohydrate modification has not been a specific focus. Longterm strategies for maintaining healthy lifestyle practices are lacking. The purpose of this application was to examine the effectiveness of a GLB traditional post-core (TPC) program compared to a carbohydrate modification and hunger focus post-core (CPC) program. Both TPC and CPC consisted of 9 monthly support sessions following completion of identical 12 weekly GLB sessions. The primary outcome was weight change; secondary outcomes included HbA1c, fasting glucose and lipid profile, systolic and diastolic blood pressure (SBP, DPB), and waist circumference (WC). A total of 60 participants with pre-diabetes and/or the metabolic syndrome were enrolled in four intervention groups. After completion of the initial 12 GLB sessions, participants were randomly assigned by group to TPC ( $N=31)$ or CPC $(N=29)$. Between baseline and 4 months, by intention-to-treat analysis, similar significant weight loss was noted in both groups (TPC $-4.0 \%$ vs. CPC $-4.5 \%, p=0.41$ ), along with significant decreases in HbA1c, SBP, DBP, and WC; no differences were noted between TPC and CPC groups. Assessments were also conducted 8 and 12 months from baseline. At 8 months the CPC program initially showed a significant fall in $\operatorname{HbA1c}(p=0.01)$; however, no significant fall was seen for TPC. At 12 months, similar significant weight loss (from baseline) was maintained by both groups (TPC-2.6\% vs. CPC $-3.8 \%, p=0.31$ ) and similar significant decreases in SBP, DBP and WC were also noted. However, there were no differences between the groups for any measure. These results suggest that both post-core strategies were successful in maintaining a reduction in diabetes and CVD risk factors at 12 months.
\end{abstract}

Keywords: Diabetes prevention; Lifestyle intervention; Prediabetes; Metabolic syndrome; Group lifestyle balance; Diabetes prevention program

Abbreviations: BMI: Body Mass Index; BP: Blood Pressure; CPC: Carbohydrate Reduction and Hunger Focus Post-core; CVD: Cardiovascular Disease; DBP: Diastolic Blood Pressure; DPP: Diabetes Prevention Program; DPSC: Diabetes Prevention Support Center; GLB: Group Lifestyle Balance; SBP: Systolic Blood Pressure; TPC: Traditional Post-core; WC: Waist Circumference

\section{Introduction}

Type 2 diabetes is a chronic and debilitating disease affecting millions of Americans [1]. It is estimated that approximately 79 million adults in the United States have pre-diabetes, a condition that increases risk for the development of type 2 diabetes [1]. Evidence that lifestyle intervention can prevent or delay type 2 diabetes and improve health outcomes in those at high risk has been derived from several clinical trials including the Diabetes Prevention Program (DPP) [2]. The translation of these lifestyle interventions into real life models was the impetus for the establishment of the Diabetes Prevention Support Center (DPSC) of the University of Pittsburgh, led by University of Pittsburgh faculty who were originally part of the DPP [3].

The mission of the DPSC is to disseminate evidence-based diabetes prevention intervention within the community setting, specifically the Group Lifestyle Balance (GLB) program which is an adaptation of the original DPP lifestyle intervention. The GLB program is a groupdelivered intervention that focuses on a healthy, lower fat diet, weight loss and physical activity. The original program consists of 12 core sessions that are delivered over a period of 12-14 weeks, and is directed at those with pre-diabetes and/or the metabolic syndrome. The GLB program has been evaluated in several community settings and has been shown to be effective in lowering risk factors for both diabetes and the metabolic syndrome [3-7]. In an effort to promote long-term diet and physical activity changes post-core sessions have been added to the program, resulting in treatment duration of one year.

While it is evident that behavioral lifestyle intervention is effective in the short term, innovative strategies are needed to promote selfmanagement for diabetes prevention and cardiovascular disease risk reduction over the long-term. Research has indicated that dietary carbohydrate reduction may be beneficial in facilitating weight loss and reducing components of risk $[8,9]$, as well as enhancing satiety [10]; however, research on the effect of these components when added to a long-term self-management program to lower risk for diabetes and cardiovascular disease is limited. Thus, the purpose of the current project was to determine the effectiveness of adding a dietary

*Corresponding author: M. Kaye Kramer, DrPH, University of Pittsburgh Graduate School of Public Health, 3512 Fifth Avenue, Pittsburgh, PA 15213, Tel: (412) 383-1680; Fax: (412) 383-1974; E-mail: mkk3@pitt.edu

Received November 22, 2011; Accepted February 18, 2012; Published February 23, 2012

Citation: Kramer MK, Venditti Elizabeth M, Semler Linda N, Kriska Andrea M, Mille Rachel G, et al. (2012) Long-term Strategies for Diabetes Prevention: Evaluation of the Group Lifestyle Balance Post-Core Sessions Focusing on Carbohydrate and Hunger Management. J Diabetes Metab S2:006. doi:10.4172/2155-6156.S2-006

Copyright: (c) 2012 Kramer MK, et al. This is an open-access article distributed under the terms of the Creative Commons Attribution License, which permits unrestricted use, distribution, and reproduction in any medium, provided the original author and source are credited. 
Citation: Kramer MK, Venditti Elizabeth M, Semler Linda N, Kriska Andrea M, Miller Rachel G, et al. (2012) Long-term Strategies for Diabetes Prevention: Evaluation of the Group Lifestyle Balance Post-Core Sessions Focusing on Carbohydrate and Hunger Management. J Diabetes Metab S2:006. doi:10.4172/2155-6156.S2-006

Page 2 of 6

component focusing on healthy carbohydrate intake and hunger management to the GLB post-core sessions.

\section{Research Design and Methods}

\section{Design}

This project utilized a post-intervention randomized study design. Participants were enrolled in four GLB intervention groups, completed the initial 12 core sessions over a 12-14 week period, and were then randomized by group to traditional post-core sessions (TPC) or TPC plus a carbohydrate and hunger management focus (CPC). The goal was to enroll a total of 60 participants to the program.

\section{Setting}

The project was implemented in two settings: the first within an urban University campus and the second at a suburban YMCA. The on-campus location is central to the University; the YMCA is located in a suburban area about twenty miles from Pittsburgh.

\section{Participant eligibility and recruitment}

The eligibility requirements for this project were intentionally broad to allow for widespread recruitment of high-risk individuals from the community, while ensuring that any person who was medically inappropriate for a lifestyle change program would be excluded. Nondiabetic individuals at least 18 years old with a body mass index (BMI) $\geq 25 \mathrm{~kg} / \mathrm{m}^{2}$ who had pre-diabetes (defined as a fasting glucose $100-125$ $\mathrm{mg} / \mathrm{dl}$ ) [11] and/or the metabolic syndrome (National Cholesterol Education Program ATPIII (NCEP-ATPIII) definition) [12] were eligible for enrollment.

Previous lab work completed in the medical setting within the year prior to enrollment was utilized for documentation of these conditions for eligibility. Individuals with a previous diagnosis of diabetes, women who were currently (or within past 6-weeks) pregnant or lactating, any person deemed by their physician not to be a candidate, or any person who was planning to leave the area before the end of the study were not eligible.

Recruitment for this project began in April, 2009. Initially, the University of Pittsburgh campus faculty and staff were targeted. A total of 16, 724 recruitment flyers were sent via University campus mail, and announcements were placed in local news sources. Concurrently, the researchers also met several times with the YMCA director to plan for implementation of the GLB program at this site. Information about the GLB program and study was included in a YMCA newsletter that was sent out to all members. In addition, flyers with information about the GLB program and study were mailed to selected zip codes within a 4 mile radius of the YMCA; 15,281 flyers were mailed. A total of 231 individuals responded to recruitment efforts initiated at both the University and YMCA; 191 completed an initial phone screening to determine their age, diabetes status, if they were planning to remain in the area during the course of the study, and BMI. Of those screened, 174 individuals met the initial phone screening criteria.

The second part of the screening for eligibility for this study required that individuals have a referral completed by their health care provider which included their clinical lab test results to confirm prediabetes and/or the metabolic syndrome. Of those who met the phone screen eligibility criteria, 82 met eligibility criteria, 32 were not eligible, 53 individuals did not provide a physician referral, thus eligibility could not be confirmed, and 7 decided they were not interested. Of the total number confirmed to meet eligibility, 60 individuals were enrolled, meeting the study goal; individuals who remained interested but who were not able to enroll due to study enrollment restrictions were advised to follow up with their health provider, and directed to the National Diabetes Education Program Small Steps, Big Rewards campaign for further information [13]. Participants chose their preferred time and location for intervention, with 27 subsequently enrolled at the University site (15 individuals chose a noon class, and 12 chose to take part in the evening) and 33 at the YMCA (15 and 18 in two evening classes)

\section{Coach training and intervention}

The GLB program was delivered by two health professionals who had completed a GLB training workshop provided by the DPSC [3] They also received additional training specifically for delivery of the CPC sessions. The health professional for the University setting was an exercise specialist with previous experience in delivery of the GLB program. The health professional who implemented the program at the YMCA was a registered dietitian with previous group leader experience.

The GLB program is a group behavioral lifestyle intervention adapted from the DPP lifestyle intervention with the same goals for weight loss and physical activity as the DPP, including achievement of a weight loss of $7 \%$ from starting weight, and an increase in physical activity to 150 minutes/week [3]. The initial program consisted of 12 core sessions delivered over 12-14 weeks. During the core phase, participants met weekly at the sites with each session lasting approximately one hour; all participants received GLB participant handouts, self-monitoring booklets, a fat and calorie tracking book, and a pedometer.

In an effort to enhance weight loss and facilitate long-term continuation of learned healthy lifestyle behaviors, the DPSC expanded the GLB intervention to include nine monthly follow-up sessions. The aim was to transition participants from weekly to monthly sessions offering the complete program (21 sessions) over a one-year period. The traditional post-core sessions included three sessions each that focused on nutrition, physical activity, and behavior (TPC). These sessions were developed based on post-core session material from the original DPP, and were designed to provide ongoing support for lifestyle change. Participants were weighed monthly and the group sessions continued to focus on reinforcement of the healthy eating and physical activity behaviors learned. Although carbohydrates were addressed in the nutritional sessions, carbohydrate intake as specifically related to hunger management was not a focus.

For this project, a specific protocol that focused on reducing poor choice/less healthy carbohydrate and improving hunger management during the post-core was developed (CPC). The CPC included additional information on these issues at each monthly post-core session. Specifically, sessions included information on reducing less healthy carbohydrate, choosing healthier carbohydrate, monitoring carbohydrate quality, identifying hunger versus craving, dealing with food cravings, and increasing satiety. Participants assigned to CPC were asked to record their intake of better/healthier carbohydrate foods such as high fiber cereals, vegetables, fruit, etc. versus less desirable choices such as sugar added foods, desserts, high sugar drinks, etc, with the goal of limiting poor/less healthy carbohydrate foods or choices. Hunger management techniques were presented such as increasing the volume of food by eating more non-starchy vegetables and foods high in water content, including high fiber foods, and planning lower carbohydrate snacks. To eliminate the introduction of a potential bias due to the addition of a new concept in self-monitoring in post-core, participants 
Citation: Kramer MK, Venditti Elizabeth M, Semler Linda N, Kriska Andrea M, Miller Rachel G, et al. (2012) Long-term Strategies for Diabetes Prevention: Evaluation of the Group Lifestyle Balance Post-Core Sessions Focusing on Carbohydrate and Hunger Management. J Diabetes Metab S2:006. doi:10.4172/2155-6156.S2-006

Page 3 of 6

assigned to TPC were asked to monitor their rate of perceived exertion during the post-core.

Both groups were also offered the opportunity to join the YMCA with the membership fee waived, and one month of membership at no charge. This was introduced at Session 8 for both groups, and included access to all of the Greater Pittsburgh YMCAs.

\section{Outcome measures}

The primary outcomes of the intervention for both groups were weight loss and achievement of the study goals between postintervention and the 8 and 12 month assessments. Secondary outcome measures included changes in fasting glucose, HbA1c, HDL cholesterol, LDL cholesterol and triglyceride levels, as well as abdominal obesity and hypertension status. Enrolled participants completed baseline and post-intervention assessments at approximately 4, 8 and 12 months post-enrollment.

Trained members of the research team collected all clinical measures for the project. Total cholesterol, high-density lipoprotein (HDL) cholesterol, low-density lipoprotein (LDL) cholesterol, triglycerides and fasting plasma glucose were measured after at least an eight-hour fast using the Cholestech LDX System, and $\mathrm{HbA} 1 \mathrm{c}$ was measured using a DCA machine by a certified research assistant. Participants received their results at each assessment visit. Medication use was assessed via participant interview. In addition, participants were weighed at each group session.

\section{Randomization}

Participants completed the initial 12 core sessions and then were randomly assigned by original group at each site to either TCP or CPC. Participants were informed of their random group assignment at their post-intervention assessment. Thus, there was one group assigned to TCP and one to CPC at both the University campus site and the YMCA, for a total of 2 groups assigned to each intervention.

\section{Statistical analysis}

The delivery of the lifestyle intervention program (GLB) core and post core was evaluated primarily by the achievement of weight loss, which was assessed at each session. For primary evaluation purposes the baseline measure and post-intervention assessment values were tested using a paired $t$ test or the non-parametric equivalent when warranted. Additional measures collected at 8 and 12 months post-enrollment were also examined in both groups to determine difference between the groups and sustainability over time. Thus all measures collected, at each of the time points, were assessed using repeated measures analysis. Intention to treat analyses were performed; for those with missing weights at the post-intervention, 8 and 12 month visits, the last documented observation was carried forward. This information was available from the session data, where weight was collected weekly; however, this was not possible for glucose and the metabolic syndrome measures as these were only collected at the assessment visits. For these measures, the last documented observed result was used. Participants with medication changes were excluded from the relevant data analysis. The changes in other cardiovascular risk factors measured (waist circumference, blood pressure, lipids) were also examined.

\section{Sample size/power estimates}

The sample size estimates presented below are based on measures of weight, specifically the mean weight loss. Based on the weight loss seen in previous GLB evaluation, and similar to the trend seen in the
DPP at approximately 3 months, we estimated that for alpha $=0.05$ and with 30 subjects in two groups each assigned to TCP and CPC (for a total of 60 participants in the study), we would have greater than $90 \%$ power to detect a $3.5 \%$ weight loss in each intervention group. It was estimated that these numbers would be sufficient to allow $80 \%$ power if attrition reaches $20 \%$.

\section{Results}

The demographic and clinical measure baseline characteristics for the 60 enrolled participants are presented in Tables 1 and 2. The mean age of the participants was 54.7 years, with the majority being white $(\mathrm{n}=54,90 \%)$ and two-thirds female $(\mathrm{n}=39,65 \%)$. In addition, in the overall group, 40 individuals (67\%) demonstrated fasting glucose levels in the pre-diabetes range at baseline, 35 individuals (58.3\%) reported an immediate family history of diabetes, and 29 (48.3\%) reported a family history of heart disease. Only 2 individuals (3\%) reported smoking. There were no differences noted between the TPC and CPC groups for sex, age or race/ethnicity at baseline. The only difference in clinical measures noted between the groups at baseline was for systolic blood pressure, where those in the TPC group demonstrated significantly higher systolic blood pressure than those in the CPC group (129.1 vs. 121.4, $\mathrm{p}=0.04)$.

Participants attended an average of 9.3 of 12 core sessions, with 49 participants (82\%) attending at least 9 of the 12 core sessions. During post-core, these participants attended an average of 6 of the 9 sessions overall (67\%), with no significant differences in attendance noted between the TPC and CPC groups.

Between baseline and the post-intervention assessment, overall weight loss for the entire group was 9.5 pounds $(-4.5 \%, \mathrm{p}<0.0001)$ Significant decreases were also noted for HbAlc $(-0.13 \%,-2.1 \%$, $\mathrm{p}=0.0002)$, systolic blood pressure $(-7.3 \mathrm{~mm} / \mathrm{Hg},-5.9 \%, \mathrm{p}<0.0001)$, diastolic blood pressure $(-6.3 \mathrm{~mm} / \mathrm{Hg},-7.7 \%, \mathrm{p}<0.0001)$, waist

\begin{tabular}{|l|l|l|l|l|}
\hline & Overall $\mathbf{n = 6 0}$ & $\begin{array}{l}\text { TPC } \\
\mathbf{n = 3 1}\end{array}$ & $\begin{array}{l}\text { CPC } \\
\mathbf{n = 2 9}\end{array}$ & $\begin{array}{l}\text { P for group } \\
\text { difference }\end{array}$ \\
\hline Sex (\% female (n)) & $\begin{array}{l}65.0 \% \\
(39)\end{array}$ & $\begin{array}{l}64.5 \% \\
(20)\end{array}$ & $\begin{array}{l}65.5 \% \\
(19)\end{array}$ & 0.94 \\
\hline $\begin{array}{l}\text { Age at baseline (mean } \\
\text { (sd), range) }\end{array}$ & 54.7 & 55.9 & 53.4 & \\
\hline $\begin{array}{l}\text { Race (\% non- } \\
\text { Caucasian }(\mathrm{n}))\end{array}$ & $\begin{array}{l}(10.5) \\
(94-72\end{array}$ & $35-72$ & $\begin{array}{l}(11.6) \\
24-72\end{array}$ & 0.37 \\
\hline
\end{tabular}

Table 1: Baseline Demographics.

\begin{tabular}{|l|l|l|l|l|l|}
\hline & \multicolumn{2}{l}{ CPC Group } & \multicolumn{2}{l|}{ TPC Group } & \\
\hline Baseline Variable & n & Mean (sd) & n & Mean (sd) & p \\
\hline Weight (lbs) & 29 & $225.3(35.3)$ & 31 & $222.7(44.7)$ & 0.81 \\
\hline Total Cholesterol (mg/dl) & 29 & $173.7(39.2)$ & 31 & $182.2(41.1)$ & 0.42 \\
\hline HDL Cholesterol (mg/dl) & 29 & $41.4(11.4)$ & 31 & $45.5(15.0)$ & 0.23 \\
\hline Non-HDL Cholesterol (mg/d) & 29 & $132.3(39.6)$ & 31 & $136.7(37.7)$ & 0.66 \\
\hline LDL Cholesterol (mg/dl)* & 27 & $96.1(30.1)$ & 31 & $100.4(33.6)$ & 0.61 \\
\hline In(Triglycerides) (mg/dl) & 29 & $5.02(0.53)$ & 31 & $5.10(0.59)$ & 0.57 \\
\hline Glucose (mg/dl) & 29 & $104.3(12.2)$ & 31 & $102.4(8.4)$ & 0.48 \\
\hline HbA1c (\%) & 29 & $6.08(0.45)$ & 31 & $5.91(0.37)$ & 0.11 \\
\hline SBP (mmHg) & 29 & $\mathbf{1 2 1 . 4 ( 1 0 . 9 )}$ & 31 & $129.1(17.2)$ & 0.04 \\
\hline DBP (mmHg) & 29 & $82.1(10.1)$ & 31 & $83.0(10.0)$ & 0.71 \\
\hline Waist (inches) & 29 & $43.6(4.9)$ & 31 & $43.4(5.6)$ & 0.85 \\
\hline BMI $\left(\mathrm{kg} / \mathrm{m}^{2}\right)$ & 29 & $37.4(6.1)$ & 31 & $35.7(5.0)$ & 0.26 \\
\hline
\end{tabular}

*LDL-c could not be calculated for 2 subjects

Table 2: Baseline Comparison of Clinical Measures for CPC and TPC Groups 
Citation: Kramer MK, Venditti Elizabeth M, Semler Linda N, Kriska Andrea M, Miller Rachel G, et al. (2012) Long-term Strategies for Diabetes Prevention: Evaluation of the Group Lifestyle Balance Post-Core Sessions Focusing on Carbohydrate and Hunger Management. J Diabetes Metab S2:006. doi:10.4172/2155-6156.S2-006

circumference $(-1.9$ inches, $-4.4 \%, \mathrm{p}<0.0001)$ and BMI $(-1.3 \mathrm{~kg} /$ $\left.\mathrm{m}^{2},-4.2 \%, \mathrm{p}<0.0001\right)$. At the post-intervention visit there were no significant differences in change from baseline noted in any of the clinical measures between the TPC and CPC groups.

At the 8 month assessment, significant decreases from baseline continued to be noted in the overall group for weight $(-8.4$ pounds, $-3.7 \%, \mathrm{p}<0.0001)$, HbA1c $(-0.20 \%,-3.3 \%, \mathrm{P}<0.001)$, systolic blood pressure $(-10.5 \mathrm{~mm} / \mathrm{hg},-8.3 \%, \mathrm{p}<0.0001)$ diastolic blood pressure $(-9.6 \mathrm{~mm} / \mathrm{Hg},-11.6 \%, \mathrm{p}<0.001)$, waist circumference $(-2.2$ inches, $-5.1 \%, \mathrm{p}<0.0001)$, and BMI $\left(-1.3 \mathrm{~kg} / \mathrm{m}^{2},-3.7 \%, \mathrm{p}<0.0001\right)$. In addition, significant increases were noted in HDL cholesterol $(+3.9 \mathrm{mg} / \mathrm{dl}$, $+9.1 \%, \mathrm{p}=0.003)$ total cholesterol $(+11.0, \mathrm{mg} / \mathrm{dl},+6.3 \%, \mathrm{p}=0.0030)$ and LDL cholesterol $(+7.2 \mathrm{mg} / \mathrm{dl},+7.6 \%, \mathrm{p}=0.02)$ (data not shown).

Data from the post-intervention to 8 month assessment visit for the specific groups are shown in Table 3. Significant increases in HDL cholesterol were noted in both groups. In addition, a significant decrease in $\mathrm{HbAlc}$ was noted for the CPC group, as well as a significant increase in total cholesterol; however, these changes were not, nor were any others, significantly different than the changes seen in the TPC group. When examined by gender, women lost an average of $0.83 \mathrm{lbs}$ in the CPC group during this time period, but gained an average of $2.3 \mathrm{lbs}$ in the TPC group $(p=0.05)$. Men gained weight in both groups $(+2.0 \mathrm{lbs}$ in the CPC group and $+1.7 \mathrm{lbs}$ in the TPC group (NS)).

At the 12 month assessment, overall weight loss from baseline for the entire group remained significant $(-7.2$ pounds, $-3.2 \%, \mathrm{p}<0.0001)$, and significant decreases in triglycerides $(-0.15 \mathrm{mg} / \mathrm{dl},-2.9 \%, \mathrm{p}=0.005)$, glucose $(-2.5 \mathrm{mg} / \mathrm{dl},-2.4 \%, \mathrm{p}=0.02)$, HbAlc $(-0.11 \%,-1.8 \%, \mathrm{p}=0.003)$, systolic blood pressure $(-7.6 \mathrm{~mm} / \mathrm{Hg},-6.0 \%, \mathrm{p}<.0001)$ diastolic blood pressure $(-8.5 \mathrm{mmHg},-10.2 \%, \mathrm{p}<.0001)$, waist circumference $(-2.0$ inches, $-2.8 \%, \mathrm{p}<.0001)$, and BMI $\left(-1.2 \mathrm{~kg} / \mathrm{m}^{2},-3.3 \%, \mathrm{p}<.0001\right)$ were noted. A significant increase in LDL cholesterol was also noted $(+7.5$ $\mathrm{mg} / \mathrm{dl},+7.9 \%, \mathrm{p}=0.001$ ) (data not shown).

Data reflecting the outcome measures by randomized treatment group at the 4 month post intervention and the 12 month assessment visits are presented in Table 4 . Within the TPC group, a significant increase in weight was noted between the 4 and 12 month assessments. However, there was no significant difference between the TPC and CPC groups and overall weight loss for the TPC group from baseline to 12 months remained significant $(-5.8$ pounds, $-2.6 \%, \mathrm{p}=0.006)$. The TPC group also demonstrated a significant decrease in triglycerides between post-intervention and 12 months $(-23 \mathrm{mg} / \mathrm{dl},-12.8 \%, \mathrm{p}=0.003)$.

Significant increases in total and LDL cholesterol were noted in the CPC group from 4 to the 12 month assessment. There were no significant changes noted between the TPC and CPC groups for any of the outcome measures, with the exception of total cholesterol, which increased in the CPC but not in the TPC group $(+6.2 \%$ v. $-2.4 \%$, $\mathrm{p}=0.003$ ). This difference only occurred in women, who had average increase in total cholesterol of $4.25 \%$ in CPC group during this time period, but an average decrease of $4.0 \%$ in the TPC group ( $\mathrm{p}=0.007)$. Men had increased total cholesterol in both groups $(+16.6 \%$ and $3.1 \%$ in the CPC and TPC group, respectively (NS)).

\section{Conclusion}

These overall results indicate that weight loss and reduction in risk factors for CVD and diabetes persist at one year after baseline for participants in the GLB program who took part in both traditional and carbohydrate/hunger management post-core sessions. There does not appear to be a significant difference between the two postcore intervention strategies. While the CPC group initially showed a significant fall in HbA1c ( $\mathrm{p}=0.01$ ) four months after beginning the post-core carbohydrate focus intervention, there was no significant difference between the two randomized treatment groups. In contrast, during this time the total cholesterol rose in the CPC group simultaneously but not in the TPC group. Nevertheless, between the 4 and the 12 month assessments there were essentially no differences between the groups for any measure, with the exception of total cholesterol, which remained significantly higher in the CPC compared to the TPC group.

\section{Discussion}

Similar to previous GLB implementation [3] and other intervention

\begin{tabular}{|c|c|c|c|c|c|c|c|c|c|c|c|c|c|}
\hline & \multicolumn{6}{|c|}{ CPC Group } & \multicolumn{6}{|c|}{ TPC Group } & \multirow[b]{2}{*}{$\begin{array}{l}\text { p-value for } \\
\text { Difference in } \\
\text { Change Between } \\
\text { Maintenance } \\
\text { Groups }\end{array}$} \\
\hline Variable & n & $\begin{array}{l}\text { 4-month } \\
\text { Mean (sd) }\end{array}$ & $\begin{array}{l}\text { 8-Month } \\
\text { Mean (sd) }\end{array}$ & $\begin{array}{l}\text { Mean } \\
\text { Change } \\
\text { (sd) }\end{array}$ & $\%$ Change & p & n & $\begin{array}{l}\text { 4-month } \\
\text { Mean (sd) }\end{array}$ & $\begin{array}{l}\text { 8-Month } \\
\text { Mean (sd) }\end{array}$ & $\begin{array}{l}\text { Mean } \\
\text { Change } \\
\text { (sd) }\end{array}$ & $\begin{array}{l}\% \\
\text { Change }\end{array}$ & $\mathbf{p}$ & \\
\hline Weight (lbs) & 29 & $214.8(34.2)$ & $215.0(33.5)$ & $+0.2(7.1)$ & $+0.1 \%$ & 0.83 & 31 & $214.0(44.8)$ & $216.1(45.3)$ & $+2.1(5.9)$ & $+1.0 \%$ & 0.07 & 0.25 \\
\hline $\begin{array}{l}\text { Total Cholesterol } \\
(\mathrm{mg} / \mathrm{dl})^{*}\end{array}$ & 28 & $172.3(45.4)$ & $187.7(42.7)$ & $\begin{array}{l}+15.4 \\
(23.7)\end{array}$ & $+8.9 \%$ & 0.0005 & 27 & $183.6(29.5)$ & $192.2(33.7)$ & $+8.6(23.2)$ & $+4.7 \%$ & 0.09 & 0.28 \\
\hline $\begin{array}{l}\text { HDL Cholesterol } \\
(\mathrm{mg} / \mathrm{dl})^{*}\end{array}$ & 28 & $41.7(11.4)$ & $46.8(14.2)$ & $+5.1(6.4)$ & $+12.2 \%$ & $<.0001$ & 27 & $45.4(13.1)$ & $48.3(15.3)$ & $+2.9(7.0)$ & $+6.4 \%$ & 0.04 & 0.24 \\
\hline $\begin{array}{l}\text { LDL Cholesterol } \\
(\mathrm{mg} / \mathrm{dl})^{*}\end{array}$ & 27 & $99.1(39.2)$ & $104.9(31.3)$ & $+5.8(23.3)$ & $+5.9 \%$ & 0.06 & 27 & $101.0(24.9)$ & $106.2(28.8)$ & $+5.2(20.0)$ & $+5.1 \%$ & 0.18 & 0.92 \\
\hline $\begin{array}{l}\text { In(Triglycerides) } \\
(\mathrm{mg} / \mathrm{dl})^{*+}\end{array}$ & 27 & $5.03(0.48)$ & $5.03(0.55)$ & $\begin{array}{l}-0.006 \\
(039)\end{array}$ & $-0.1 \%$ & 0.64 & 27 & $5.13(0.44)$ & $5.13(0.50)$ & $\begin{array}{l}-0.003 \\
(0.22)\end{array}$ & $-0.06 \%$ & 0.74 & 0.98 \\
\hline Glucose $(\mathrm{mg} / \mathrm{dl})^{*+}$ & 27 & $101.9(13.0)$ & $102.1(10.9)$ & $+0.2(6.9)$ & $+0.2 \%$ & 0.92 & 31 & $104.1(10.2)$ & $105.3(10.9)$ & $+1.2(4.7)$ & $+1.2 \%$ & 0.43 & 0.63 \\
\hline $\mathrm{HbA} 1 \mathrm{c}(\%)^{*}$ & 28 & $5.92(0.44)$ & $5.83(0.45)$ & $\begin{array}{l}-0.08 \\
(0.18)\end{array}$ & $-1.4 \%$ & 0.01 & 31 & $5.80(0.34)$ & $5.74(0.32)$ & $\begin{array}{l}-0.06 \\
(0.18)\end{array}$ & $-1.0 \%$ & 0.10 & 0.52 \\
\hline $\mathrm{SBP}(\mathrm{mmHg})^{*}$ & 24 & $115.9(10.3)$ & $112.3(9.7)$ & $-3.6(10.8)$ & $-3.1 \%$ & 0.19 & 27 & $120.6(11.6)$ & $120.1(17.2)$ & $\begin{array}{l}-0.43 \\
(10.5)\end{array}$ & $-0.36 \%$ & 0.57 & 0.29 \\
\hline $\mathrm{DBP}(\mathrm{mmHg})$ * & 24 & $76.3(8.5)$ & $73.2(10.5)$ & $-3.2(8.8)$ & $-4.2 \%$ & 0.20 & 27 & 76.6 (9.2) & 74.5 (10.9) & $-2.1(7.0)$ & $-2.7 \%$ & 0.13 & 0.64 \\
\hline Waist (inches) & 29 & $41.4(5.0)$ & $41.1(4.8)$ & $-0.2(1.4)$ & $-0.5 \%$ & 0.22 & 31 & $41.8(5.9)$ & $41.4(6.1)$ & $-0.4(1.3)$ & $-1.0 \%$ & 0.15 & 0.64 \\
\hline $\mathrm{BMI}\left(\mathrm{kg} / \mathrm{m}^{2}\right)$ & 29 & $35.7(6.0)$ & $35.7(5.7)$ & $+0.02(1.1)$ & $+0.1 \%$ & 0.81 & 31 & $34.4(5.3)$ & $34.7(5.6)$ & $+0.4(1.0)$ & $+1.1 \%$ & 0.07 & 0.20 \\
\hline
\end{tabular}

*Participants with medication changes excluded, $\dagger$ excluded 1 not fasting

Table 3: Randomization (4-month) v. 8-Month Assessment. 
Citation: Kramer MK, Venditti Elizabeth M, Semler Linda N, Kriska Andrea M, Miller Rachel G, et al. (2012) Long-term Strategies for Diabetes Prevention: Evaluation of the Group Lifestyle Balance Post-Core Sessions Focusing on Carbohydrate and Hunger Management. J Diabetes Metab S2:006. doi:10.4172/2155-6156.S2-006

Page 5 of 6

\begin{tabular}{|c|c|c|c|c|c|c|c|c|c|c|c|c|c|}
\hline & \multicolumn{6}{|c|}{ CPC Group } & \multicolumn{6}{|c|}{ TPC Group } & \multirow[b]{2}{*}{$\begin{array}{l}\text { p-value for } \\
\text { Difference in } \\
\text { Change Between } \\
\text { Maintenance } \\
\text { Groups }\end{array}$} \\
\hline Variable & $\mathbf{n}$ & $\begin{array}{l}\text { 4-Month } \\
\text { Mean (sd) }\end{array}$ & $\begin{array}{l}\text { 12-Month } \\
\text { Mean (sd) }\end{array}$ & $\begin{array}{l}\text { Mean } \\
\text { Change } \\
\text { (sd) }\end{array}$ & $\begin{array}{l}\% \\
\text { Change }\end{array}$ & p & $\mathbf{n}$ & $\begin{array}{l}\text { 4-Month } \\
\text { Mean (sd) }\end{array}$ & $\begin{array}{l}\text { 12-Month } \\
\text { Mean (sd) }\end{array}$ & $\begin{array}{l}\text { Mean } \\
\text { Change } \\
\text { (sd) }\end{array}$ & $\begin{array}{l}\% \\
\text { Change }\end{array}$ & p & \\
\hline Weight (Ibs) & 29 & $214.8(34.2)$ & $216.6(34.5)$ & $+1.7(9.3)$ & $+0.8 \%$ & 0.34 & 31 & $214.0(44.8)$ & $216.9(44.7)$ & $+2.9(6.8)$ & $+1.4 \%$ & 0.04 & 0.58 \\
\hline $\begin{array}{l}\text { Total Cholesterol } \\
(\mathrm{mg} / \mathrm{dl})^{*}\end{array}$ & 26 & $169.1(45.5)$ & $179.5(44.5)$ & $\begin{array}{l}+10.5 \\
(15.0)\end{array}$ & $+6.2 \%$ & 0.003 & 27 & $183.6(29.5)$ & $179.2(29.7)$ & $-4.4(17.6)$ & $-2.4 \%$ & 0.24 & 0.003 \\
\hline $\begin{array}{l}\text { HDL Cholesterol } \\
(\mathrm{mg} / \mathrm{dl})^{*}\end{array}$ & 26 & $41.6(11.6)$ & $41.2(14.3)$ & $-0.35(7.0)$ & $-0.8 \%$ & 0.78 & 27 & $45.4(13.1)$ & $42.4(15.7)$ & $-3.0(8.8)$ & $-6.7 \%$ & 0.10 & 0.14 \\
\hline $\begin{array}{l}\text { LDL Cholesterol } \\
(\mathrm{mg} / \mathrm{dl})^{*}\end{array}$ & 26 & $96.2(37.7)$ & $104.8(34.0)$ & +8.6 (23.4) & $+8.9 \%$ & 0.004 & 27 & $101.0(24.9)$ & $105.4(24.7)$ & $+4.4(15.2)$ & $+4.4 \%$ & 0.14 & 0.44 \\
\hline $\begin{array}{l}\text { In(Triglycerides) } \\
(\mathrm{mg} / \mathrm{dl})^{*}\end{array}$ & 26 & $5.04(0.46)$ & $4.97(0.55)$ & $-0.07(0.32)$ & $-1.4 \%$ & 0.19 & 27 & $\begin{array}{l}5.17 \\
(0.55)\end{array}$ & $\begin{array}{l}4.93 \\
(0.49)\end{array}$ & $\begin{array}{l}-0.25 \\
0.45)\end{array}$ & $-4.8 \%$ & 0.005 & 0.15 \\
\hline Glucose $(\mathrm{mg} / \mathrm{dl})^{*}$ & 27 & $101.3(12.3)$ & $99.0(9.9)$ & $-2.3(10.4)$ & $-2.3 \%$ & 0.34 & 31 & $104.1(10.2)$ & $101.5(10.7)$ & $-2.6(9.0)$ & $-2.5 \%$ & 0.13 & 0.91 \\
\hline $\mathrm{HbA} 1 \mathrm{c}(\%)^{*}$ & 27 & $5.90(0.44)$ & $5.92(0.45)$ & $\begin{array}{l}+0.02 \\
(0.22)\end{array}$ & $+0.34 \%$ & 0.68 & 31 & $5.80(0.34)$ & $5.81(0.34)$ & $\begin{array}{l}+0.01 \\
(0.19)\end{array}$ & $+0.17 \%$ & 0.85 & 0.86 \\
\hline $\mathrm{SBP}(\mathrm{mmHg})^{*}$ & 21 & $116.5(10.8)$ & $117.2(10.7)$ & $+0.7(10.0)$ & $+0.06 \%$ & 0.69 & 27 & $120.6(11.6)$ & $120.7(14.0)$ & $+0.1(8.1)$ & $+0.08 \%$ & 0.98 & 0.84 \\
\hline $\mathrm{DBP}(\mathrm{mmHg})^{*}$ & 21 & 76.7 (8.9) & $76.2(9.7)$ & $-0.5(6.9)$ & $-0.7 \%$ & 0.97 & 27 & $76.6(9.2)$ & 74.5 (10.9) & $-1.7(6.7)$ & $-2.2 \%$ & 0.17 & 0.55 \\
\hline Waist (inches) & 29 & $41.4(4.9)$ & $41.4(4.6)$ & $-0.01(2.1)$ & $-0.02 \%$ & 0.85 & 31 & $41.8(5.9)$ & $41.7(5.9)$ & $-0.1(1.4)$ & $-0.2 \%$ & 0.60 & 0.82 \\
\hline BMI $\left(\mathrm{kg} / \mathrm{m}^{2}\right)$ & 29 & $35.7(6.0)$ & $35.9(6.0)$ & $+0.3(1.5)$ & $+0.8 \%$ & 0.32 & 31 & $34.4(5.3)$ & $34.8(5.4)$ & $+0.5(1.1)$ & $+1.4 \%$ & 0.03 & 0.52 \\
\hline
\end{tabular}

${ }^{*}$ Participants with medication changes excluded

Table 4: Randomization (4-month) v. 12-Month Assessment.

programs which have found decreases or little to no change in HDL cholesterol during weight loss with an increase as weight loss becomes stabilized [14-16], we noted a significant increase in HDL cholesterol in both groups at the 8 month assessment; however this effect was not evident at the 12 month assessment. In addition, increases in LDL cholesterol were noted for both groups between the 4 month postintervention and the 12 month assessments (significant in the CPC group only). This is in contrast to previous GLB program evaluations in which participants did not receive structured post-core sessions, but rather met monthly after the completion of the core to collect weight and activity minutes, and to problem solve $[3,7]$.

The benefit of low-carbohydrate, versus low-fat diet for long-term weight loss, has been the subject of ongoing debate. Recent data from a randomized clinical research trial that compared a low-carbohydrate to a low-fat diet in obese individuals found that at the end of two years of follow up, there were no differences in weight or body composition between the two groups, leading the authors to conclude that either diet may be used to achieve successful long-term weight loss when coupled with behavioral treatment [17]. However, for obese individuals the authors found that a low-carbohydrate diet had greater long-term effects on HDL cholesterol compared to a low-fat diet, but there were also more adverse symptoms reported in the low-carbohydrate group. Glucose and HbAlc were not included as measured outcomes in this trial as the study was not specifically directed toward those at risk for diabetes.

Limited translation research exists regarding strategies for long-term self-management as part of intervention specifically targeted for diabetes prevention. One example is the Montana statebased cardiovascular disease and diabetes prevention program, in which the adapted DPP Native Lifestyle Balance curriculum was utilized. Participants who completed the intervention at 10 months demonstrated significant reductions in weight and several risk factors for diabetes and cardiovascular disease [14]. Ackermann et al. describes another DPP translation project directed toward individuals at risk for diabetes that was implemented in the YMCA setting [18]. Participants attended monthly sessions after completion of a 16-session core. At
12 months, the intervention group demonstrated significant decreases in 10-year risk from baseline when compared with control subjects in the study; however, upon examination of individual risk factors, no changes, or minimal improvement in HbA1C and systolic blood pressure were noted [19].

Another example of a long-term DPP translation research study focused specifically on individuals already diagnosed with diabetes [20]. In this study by Mayer-Davis et al., participants were randomly assigned to either an intensive-lifestyle intervention that was modeled on the DPP, a "reimbursable-lifestyle" which is described as "intensivelifestyle intervention delivered in the time allotted for Medicare reimbursement for diabetes education related to nutrition and physical activity" intervention, or to usual care [20]. At 12 months, the authors found that a greater proportion of intensive-lifestyle participants lost $2 \mathrm{~kg}$ or more than usual-care participants; however, no differences in weight change were observed between reimbursable-lifestyle and usualcare participants. A significant decrease in glycated hemoglobin across all of the groups was also noted, but this decrease was not different between groups [20].

Thus, while data continues to emerge to support the successful translation of short-term primary diabetes prevention intervention in the community, information regarding strategies to help individuals sustain healthy lifestyle practices for the prevention of diabetes over the long run is lacking. This project did not demonstrate a difference between carbohydrate-focused maintenance compared to a traditional maintenance program. This may be due to the fact that both groups were exposed to basic information regarding overall healthy carbohydrate choices during the initial phase of treatment, and followed a reduced fat and calorie plan which would likely lower carbohydrate intake. In summary, it appears that the continued contact and support was more robust than the particular focus of self-monitoring during the maintenance sessions.

Strengths of this translational research project include a randomized, prospective design that allowed for evaluation of strategies for longterm self-management in diabetes prevention intervention. In addition, we enrolled individuals at risk for diabetes and cardiovascular disease, 
Citation: Kramer MK, Venditti Elizabeth M, Semler Linda N, Kriska Andrea M, Miller Rachel G, et al. (2012) Long-term Strategies for Diabetes Prevention: Evaluation of the Group Lifestyle Balance Post-Core Sessions Focusing on Carbohydrate and Hunger Management. J Diabetes Metab S2:006. doi:10.4172/2155-6156.S2-006

and although still lower than desired, approximately one-third of those enrolled were male. We have also developed and described a post-core curriculum that is available for public use at www.diabetesprevention. pitt.edu. A limitation of the project is that the sample size was relatively small and included primarily white individuals, therefore these results may not be generalizable to other groups or races/ethnicities. It is also possible that because the same health professionals delivered both the TPC and CPC interventions, there may have been some contamination between the groups. It should also be noted that while reduction in less healthy carbohydrate was a key focus of the CPC intervention, the CPC was not a carbohydrate restricted, i.e. carbohydrate counting, diet, and thus may not be directly comparable to other studies which focus on carbohydrate reduction through carbohydrate counting.

As we move forward with diabetes prevention efforts, the development and evaluation of innovative post-core strategies that are readily translatable to community programs will be essential. In this report, both traditional and carbohydrate focused strategies persisted in sustaining healthy lifestyle changes and a reduction in risk factors for diabetes and CVD. Further research in this area is warranted.

\section{Acknowledgement}

Funding provided by Robert C. and Veronica Atkins Foundation. We would also like to acknowledge the lifestyle coaches for this project, Jo Ellen Brewton, MSW, MS and Lisa Martich, RD, LD, as well as the staff of the Baierl Family YMCA

\section{References}

1. Centers for Disease Control and Prevention (2011) National diabetes fact sheet: national estimates and general information on diabetes and prediabetes in the United States, 2011. Atlanta, GA: U.S. Department of Health and Human Services, Centers for Disease Control and Prevention.

2. Knowler W, Barrett-Connor E, Fowler S, Hamman R, Lachin J, et al. (2002) Reduction in the incidence of type 2 diabetes with lifestyle intervention or metformin. N Engl J Med 346: 393 - 403

3. Kramer MK, Kriska AM, Venditti EM, Miller RG, Brooks MM, et al. (2009) Translating the Diabetes Prevention Program: A Comprehensive Model for Prevention Training and Program Delivery. American Journal of Preventive Medicine 37: 505-511.

4. McTigue KM, Conroy MB, Bigi L, Murphy C, McNeil M (2009) Weight Loss Through Living Well: Translating an Effective Lifestyle Intervention Into Clinical Practice. Diabetes Educator 35: 199-208.

5. Seidel MC, Powell RO, Zgibor JC, Siminerio LM, Piatt GA (2008) Translating the Diabetes Prevention Program Into an Urban Medically Underserved Community: A nonrandomized prospective intervention study. Diabetes Care 31: $684-689$

6. Kramer MK, Kriska AM, Venditti EM, Semler LN, Miller RG, et al. (2010) A novel approach to diabetes prevention: Evaluation of the Group Lifestyle Balance program delivered via DVD. Diabetes Research and Clinical Practice 90: e60-e63.

7. Kramer MK, McWilliams JR, Chen H-Y, Siminerio LM (2011) A CommunityBased Diabetes Prevention Program. The Diabetes Educator 37: 659-668.

8. Shai I, Schwarzfuchs D, Henkin Y, Shahar DR, Witkow S, et al. (2008) Weigh Loss with a Low-Carbohydrate, Mediterranean, or Low-Fat Diet. N Engl J Med 359: 229-241.

9. Gardner CD, Kiazand A, Alhassan S, Kim S, Stafford RS, et al. (2007) Comparison of the Atkins, Zone, Ornish, and LEARN Diets for Change in Weight and Related Risk Factors Among Overweight Premenopausal Women The A TO Z Weight Loss Study: A Randomized Trial. JAMA 297: 969-977.

10. Kushner RF, Doerfler B (2008) Low-carbohydrate, high-protein diets revisited. Curr Opin Gastroenterol. 24: 198-203.

11. (2004) Diagnosis and Classification of Diabetes Mellitus. Diabetes Care 27: S5-10.

12. Expert Panel on Detection, Evaluation, and Treatment of High Blood Cholestero in Adults (2001) Executive Summary of The Third Report of The National Cholesterol Education Program (NCEP) Expert Panel on Detection, Evaluation, And Treatment of High Blood Cholesterol In Adults (Adult Treatment Panel III) JAMA 285: 2486-2497.

13. Centers for Disease Control and Prevention: National Diabetes Education Program.

14. Vanderwood KK, Hall TO, Harwell TS, Butcher MK, Helgerson SD, et al. (2010) Implementing a State-Based Cardiovascular Disease and Diabetes Prevention Program. Diabetes Care 33: 2543-2545.

15. Fox A, Thompson J, Butterfield G, Gylfadottir U, Moynihan S, et al. (1996) Effects of diet and exercise on common cardiovascular disease risk factors in moderately obese older women. The American Journal of Clinical Nutrition 63 : 225-233.

16. Dattilo A, Kris-Etherton $P$ (1992) Effects of weight reduction on blood lipids and lipoproteins: a meta- analysis. The American Journal of Clinical Nutrition 56: $320-328$.

17. Foster GD, Wyatt HR, Hill JO, Makris AP, Rosenbaum DL, et al. (2010) Weight and metabolic outcomes after 2 years on a low-carbohydrate versus low-fat diet: a randomized trial. Ann Intern Med 153: 147-157.

18. Ackermann RT, Finch EA, Brizendine E, Zhou H, Marrero DG (2008) Translating the Diabetes Prevention Program into the Community: The DEPLOY Pilo Study. American Journal of Preventive Medicine 35: 357-363.

19. Lipscomb ER, Finch EA, Brizendine E, Saha CK, Hays LM, et al. (2009) Reduced 10-Year Risk of Coronary Heart Disease in Patients Who Participated in a Community-Based Diabetes Prevention Program. Diabetes Care 32: 394 396

20. Mayer-Davis EJ, D'Antonio AM, Smith SM, Kirkner G, Levin Martin S, et al (2004) Pounds Off With Empowerment (POWER): A Clinical Trial of Weigh Management Strategies for Black and White Adults With Diabetes Who Live in Medically Underserved Rural Communities. Am J Public Health 94: 1736-1742. 